\title{
From cell motility to flow cytometry
}

\section{This week a scattering of research products encompasses both the unusual and the pragmatic.}

IN what may be a coup for the company, ICN ImmunoBiologicals has delivered a monoclonal ELISA kit that types the four

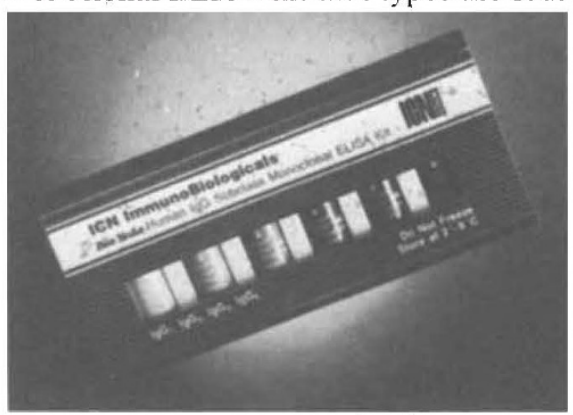

Fine distinctions from monoclonal methods.

subclasses of human IgG (Reader Service No. 100). Intended for research use only, ICN's $\$ 395$ (US) kit could give a boost to studies of immunodeficiency diseases, chronic respiratory infections and allergic reactions. The kit uses control serum calibrated to World Health Organization reference preparation 67/97, and provides results in one day.

A digital delay/pulse generator with resolution to 5 million millionths of a second can tackle even the most demanding applications, according to Lambda Photometrics (Reader Service No. 101). The DG535 generator has the sort of accuracy normally associated with a laser; each of the DG535's four delay channels has a $1000 \mathrm{~s}$ range and a $5 \mathrm{ps}$ resolution. With an internal trigger that operates in either single-shot or burst modes, the generator is programmable from $0.001 \mathrm{~Hz}$ to $1 \mathrm{MHz}$. Lambda sells its generator for $£ 2,550$ in the United Kingdom.

If manual methods for tracking cell movement are getting a bit tiresome, the CellTrak system from Motion Analysis could offer a way out (Reader Service No.

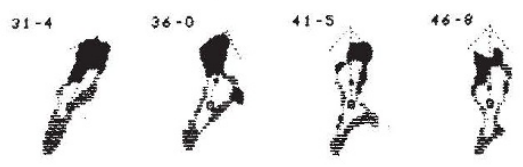

Shaped dynamics, described by CellTrak

102). The company coupled IBM PC/AT capabilities with its VP110 vidco processor to create a motility analysis package that, it says, can yield results in 10 to 20 minutes. Automated from data capture to display, CellTrak analysis has the flexibility to describe motion in terms of speed, direction, angular velocities and other parameters. The company's system, priced at approximately $\$ 35,000$ (US), can follow both bacterial and mammalian cell movement.

Ortho Diagnostic is handing out advice on flow cytometry via its new Applications Support Laboratory (Reader Service No. $103)$. Ortho's service includes a free telephone consultation line to answer questions on the method, its reagents and applications. Enrolling in the laboratory also nets the user a set of 28 protocols for flow cytometry, with privileges to whatever future applications are published in the series.

Omni Biochem has just released a catalogue that details its manufacturing services and 2,000 products for biotechnology and genetic engineering research (Reader Service No. 104). Among the catalogue's pages are descriptions of Omni's custom peptide synthesis service and a variety of biologically active peptides, enzyme substrates and inhibitors and $\mathrm{L}-$ and $\mathrm{D}$-amino
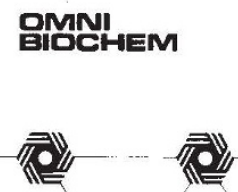

A catalogue airs the wares of Omni Biochem. acids and their derivatives. Omni also offers more than 100 special amino acids. resins and purified reagents and solvents.

A new process for preparing microorganisms could make reconstituting bacterial cultures as easy as mixing instant oatmeal (Reader Service No. 105). The American Type Culture Collection has just begun selling freeze-dried Uniplus cultures that come ready-made with the appropriate growth medium. All that's required to establish a growing broth culture is sterile water and incubation; subculturing is not necessary. Each Uniplus culture. which has a reconstituted volume of $5 \mathrm{ml}$. costs $\$ 12$ (US).

Able to process up to 7.51 of water per minute, the Fistreem UV sterilizer keeps water purification rolling (Reader Service No. 106). The UV source Fistreem uses in its sterilizer will treat water coming straight from the mains supply or out of storage. Fistreem says this flexibility

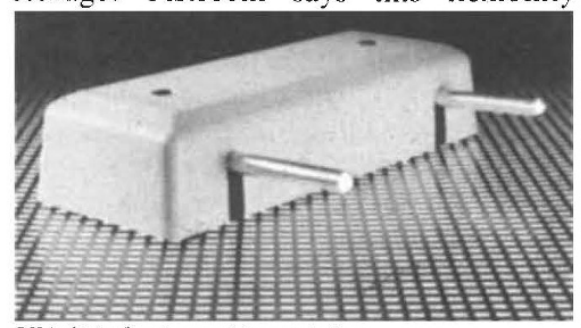

UV disinfection without delay. makes the sterilizer ideal for removing microorganisms from a recirculating system or for ensuring sterility after distillation or deionization.

These notes are compiled by Karen Wright from information provided by the manufacturers. To obtain further details about these products, use the reader service card bound inside the journal. Prices quoted are sometimes nominal and apply only within the country indicated.

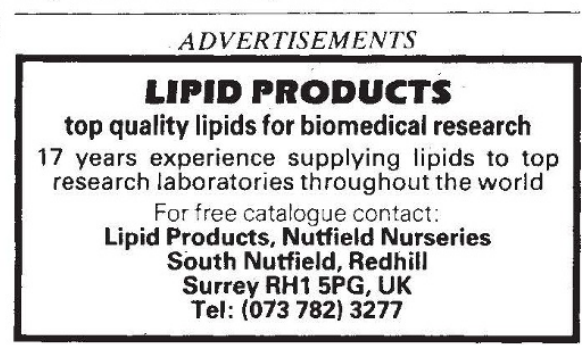

Reader Service No.19

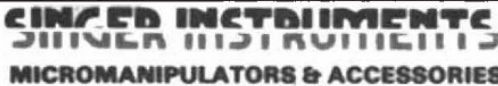
MICROMANIPULATORS \&
YEAST?

\section{TETRAD ANALYSIS?}

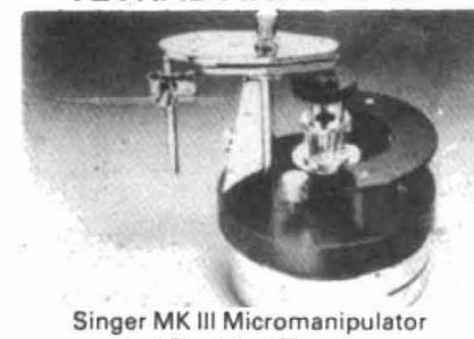
and Precision Elavator.

\section{Write direct to:}

Singer Instrument Co. Ltd.

Treborough Lodge

Roadwater, Watchet

Somerset TA23 0OL

England. Tel. (0984) 40226

Telex: 337492 Comcab G

Reader Service No.50

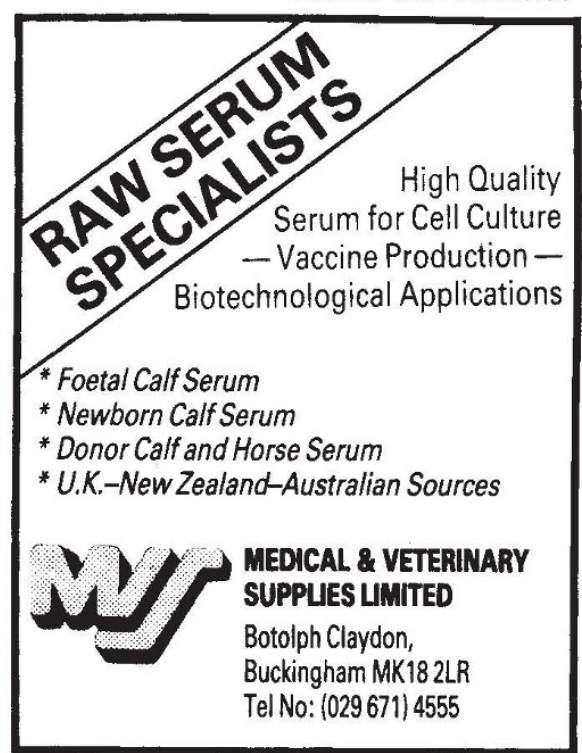

Reader Service No.9 